- conduct of clinical trials", says Ramanan Laxminarayan, vice-president of policy and research at the Public Health Foundation of India in New Delhi. Shortly after the HPV report hit the headlines, the Drugs Controller General of India produced, for the first time, draft guidelines on the reporting of adverse events in clinical trials.

Heidi Larson, an anthropologist at the London School of Hygiene \& Tropical Medicine who studies the social acceptance of vaccines, says that the collapse of the HPV trial highlights one of the key problems in research collaborations between developed and developing countries. Ultimately, she says, international researchers are obliged to work within the ethics capacity of the host country, regardless of whether or not it is robust. Trying to align different expectations over research ethics can be especially tricky, Larson adds. "How do you negotiate local versus national versus international tensions?"

Meanwhile, India's vaccination plans could suffer collateral damage from the controversy. India decided in 2008 to roll out a new pentavalent vaccine against diphtheria, pertussis, tetanus, Haemophilus influenzae type b ( Hib) and hepatitis B. Public objections over fears of dangerous side effects reported in Sri Lanka and the vaccine's high cost delayed the programme. Vaccination is finally due to start next month, but only in Tamil Nadu and Kerala, southern states chosen because their routine immunization coverage is already high, says Ajay Khera, deputy commissioner of India's Universal Immunisation Programme.

Vaccination fears that have made headlines in the West are now taking hold in countries such as India, says Larson (H. J. Larson et al. Lancet doi:10.1016/S01406736(11)60678-8; 2011). Because most of the vaccines now in development are aimed at diseases common in the developing world, such as malaria, tuberculosis, leishmaniasis and helminth infections, antivaccination movements in such countries could have a major impact on public health, adds Richard Moxon, a paediatrician at the John Radcliffe Hospital in Oxford, UK.

Jacob Puliyel, head of paediatrics at St Stephen's Hospital in Delhi, has been a vocal opponent of both the HPV vaccines and the pentavalent vaccine. He does not endorse the vaccine fears that gripped the public after the four girls' deaths, but he told Nature that too little is known about the prevalence of Hib and HPV-related cervical cancer in India to justify the new vaccines. At a time when India is already struggling to achieve universal coverage with existing vaccines - coverage for basic childhood immunizations is just $63 \%$, according to Khera - the country simply cannot afford them, Puliyel says.

\title{
Open access comes of age
}

\section{Publishing model enters phase of slower but steady growth.}

\section{BY JOHN WHITFIELD}

A study of open-access publishing published last week in the open-access journal PLOS ONE - has found that the number of papers in freely accessible journals is growing at a steady $20 \%$ per year (M. Laakso et al. PLoS ONE 6, e20961;2011). To many, the growth confirms the health of the free-access, author-pays model. But to a few it is a discouraging sign that open access is not about to take over the world of scholarly publishing.

The analysis, by information scientist Mikael Laakso of the Hanken School of Economics in Helsinki and his colleagues, also found that the number of fully open-access journals is growing at around 15\% every year as new journals are founded and subscription journals switch to the open-access model (see 'Opening up'). By contrast, subscription journals are growing at about 3.5\%. "Most indicators suggest growth is not slowing," says Laakso. "The open-access publishing model has proven itself to work."

Laakso divides the history of open access into three phases. First came the pioneering years of 1993-99, during which most open-access journals were, he says, "home-brew" efforts, set up by individuals and hosted on university servers. Next were the innovation years, which saw the birth of publishers such as the Public Library of Science and of software infrastructure that makes it much easier to launch a digital journal.

Since 2005, Laakso says, innovation has slowed but growth continues - the consolidation phase. Following this trend, last week Nature Publishing Group (NPG) launched Scientific Reports, an author-pays, open-access, online-only journal, which reviews papers on technical soundness rather than impact.

NPG's acknowledged inspiration is $P L O S$ ONE, which in 2010 published 6,749 papers, making it the world's largest journal. It has been a "phenomenal success", says Jason Wilde, business development director at NPG. "It shows that authors and readers like the model of a broad-based journal with light peer review." Scientific Reports will provide PLOS ONE with a rival and help drive up standards, says Wilde. "In any market there should be competition."

The trends "show the success of open access", says Peter Suber, director of the Open Access project at the non-profit lobby group Public Knowledge in Washington DC. So far, he adds, the open-access movement has not imperilled commercial publishers. "The predictions of harm are being proven to be false."

But not all advocates of open access are satisfied with its progress. "The growth rate is portrayed as dramatic, but it's not dramatic at all if the goal is $100 \%$ open access," says Stevan Harnad, a cognition researcher at the University of Southampton, UK. Other ways to make papers freely accessible, such as self-archiving and hybrid journals, which allow authors ò to choose whether to pay for open access, are also growing only linearly, he says. "The rate is much too low for the needs of research."

What is not known is whether open-access journals are competing with subscription journals, or whether they have opened up a publishing niche. Harnad believes that most open-access journals are new ventures. Because nearly all the must-have journals still charge subscription fees, the rise of the authorpays model actually imposes an extra expense on research funders, he says.

To escape this catch-22, says Harnad, institutions and funders - who have led the demand for open access - must mandate grantees to deposit papers published in subscription journals in open repositories. This would free up resources to support author-pays open access. "Publishers won't convert until the money is available to pay them," he says. 